\title{
MITIGASI SPRITUAL DALAM NASKAH \\ LONTAR ROGA SANGHARA BHUMI \\ Oleh
}

\author{
I Nyoman Suka Ardiyasa
}

Dosen di STAH N Mpu Kuturan Singaraja

\begin{abstract}
Abstrak
Pulau Bali adalah pulau yang sangat rentan terhadap bencana, terbukti dengan catatan sejarah bahwa Bali telah mengalami gempa bumi besar yang lebih dikenal sebagai Gejer Bali. Berbagai upaya telah dilakukan oleh masyarakat dari masa lalu hingga sekarang dalam upaya mitigasi yang dilakukan di sekala dan niskala. Di masyarakat, orang percaya bahwa jika mereka ingin menghindari bencana maka masyarakat harus menerapkan tri hita karana, sementara niskala (secara teologis) dilakukan dengan berbagai upakara. Sumber-sumber Upakara dan jenis-jenis bencana yang terjadi di dunia ini diyakini terkandung dalam naskah Lontar Roga Sanghara Bhumi. Namun keberadaan naskah ini belum banyak diketahui sehingga perlu dilakukan peninjauan yang lebih mendalam sehingga bisa disebarluaskan ke publik. Untuk fokus pada ulasan ini, kami fokus pada tiga formula masalah: menganalisis ringkasan naskah lontar Roga Sanghara Bhumi, jenis bencana yang disebutkan dalam lontar Roga Sanghara Bhumi, dan upaya teologis yang dilakukan dalam menangani bencana yang disebutkan dalam lontar Roga Sanghara Bhumi.

Dari hasil penelitian yang dilakukan diketahui secara singkat bahwa lontar Roga Sanghara Bhumi berisi tentang penyebab terjadinya bencana atau bencana yang terjadi di dunia, jenis-jenis bencana atau bencana yang dapat terjadi di dunia dan beberapa karakteristik dari bencana yang akan datang atau bencana, sedangkan jenis-jenis Bencana yang disebutkan dalam lontar Roga Sanghara Bhumi adalah jenis bencana yang mengulangi setiap sasih itu dan jenis bencana yang terjadi yang dilihat dari sikap buruknya, dalam konsep Lontar Roga Sanghara Bhumi disebut Durmanggala . Upaya teologis yang dilakukan dalam menanggulangi bencana yang disebutkan dalam lontar Roga Sanghara Bhumi sedang melakukan upacara yang ditunjukkan kepada Ida Sang Hyang Widhi Wasa dengan tujuan memohon keselamatan seperti Upacara Prayascita, Master Piduka, Labuh Gentuh, Jagat, Pamahayu Bumi dan Nangluk Mrana. Semua upacara ini adalah upaya teologis (mitigasi) dalam mengurangi risiko bencana yang terjadi di bumi.
\end{abstract}

Kata Kunci: mitigasi, teologis, naskah roga sanghara bhumi

\section{$\underline{\text { Abstract }}$}

The island of Bali is an island very vulnerable to disaster, it is proven with historical records that Bali has experienced a major earthquake better known as Gejer Bali. Various efforts have been made by the community from the past until now in the effort of mitigation done in sekala and niskala. In the community, people believe that if they want to avoid the disaster then the community must implement the tri hita karana, while niskala (theologically) done with various upakara. Upakara sources and the types of disasters that occur in this world are believed to be contained in the Lontar Roga Sanghara Bhumi manuscript. But the existence of the manuscript is not much to know so it is necessary to conduct a more in-depth review so that it can be disseminated to the public. To focus on these reviews, we focused on three problem formulas: analyzing the summary of the Roga Sanghara Bhumi lontar manuscripts, the types of disasters mentioned in the Roga Sanghara Bhumi lontar, 
and the theological attempts made in dealing with the disasters mentioned in lontar Roga Sanghara Bhumi.

From the results of the study conducted it is briefly known that the lontar Roga Sanghara Bhumi contains about the causes of catastrophe or disaster occurred in the world, the types of catastrophes or disasters that can occur in the world and some characteristics of the coming disaster or disaster, while the types The disaster mentioned in the lontar of Roga Sanghara Bhumi is a type of disaster that repeats every sasih it and the kind of disaster that occurs which is seen from the bad gesture, in the concept of Lontar Roga Sanghara Bhumi called Durmanggala. The theological efforts undertaken in tackling the disasters mentioned in the lontar of Roga Sanghara Bhumi are performing ceremonies that are shown to Ida Sang Hyang Widhi Wasa with the aim of pleading for salvation such as Prayascita Ceremony, Master Piduka, Labuh Gentuh, Jagat, Pamahayu Bumi and Nangluk Mrana. All these ceremonies are theological (mitigation) efforts in reducing disaster risks that occur on earth.

Key Word : mitigasi, teologis, roga sanghara bhumi manuscript

\section{Pendahuluan}

Sejarah mencatat Pulau Bali merupakan sebuah pulau yang sangat rawan bencana alam. Hal ini terbukti pernah terjadi peristiwa gempa bumi besar di tahun 1815. Pusat gempa bumi diperkirakan berada di laut sebelah utara kerajaan Buleleng di Bali utara. Ibukota Buleleng yaitu Singaraja mengalami kerusakan parah. Gempa bumi tersebut menggetarkan seluruh pulau Bali, sehingga disebut juga Gejer Bali yang artinya Bali bergetar. Selain di Bali, getaran kuat juga dirasakan hingga Surabaya, Lombok, bahkan Bima. (beritabali.com tanggal Selasa, 24 November 2015). Kejadian-kejadian bencana alam lainnya yang pernah terjadi di Bali tercatat Gempa pada 17 Desember 1979 di Karangasem menyebabkan 400 orang luka (sains.kompas.com). Bahkan diyakini Gempa pada tahun 1815 memberikan dampak kekacauan di seluruh Bali, hal ini sampai sekarang dapat ingat nama-nama daerah yang menunjukan keganasan gempa tersebut seperti nama desa Pancasari di Kecamatan Sukasada, Buleleng, Bali yang dulu disebut desa Benyahe (tempat yang hancur), nama Paket Agung Kecamatan Buleleng, Buleleng, Bali diyakini dahulu pernah banyak glondongan-glondongan kayu yang hanyut akibat guncangan dahsyat dari daerah penyangga tri danu (Beratan, Buyan dan Tamblingan) yang terdampar disana sehingga disebut Paket Agung.
Demikian rawannya Pulau Bali akan kejadiankejadian bencana alam sehingga membutuhkan upaya mitigasi secara fisik maupun non fisik sebab manusia tidak bisa menolak terjadinya bencana alam namun hanya bisa melakukan pengurangan terhadap resiko bencana yang terjadi. Upayaupaya yang sudah dilakukan oleh leluhur orang Bali dalam menghadapi bencana seperti membiasakan pola hidup untuk mencintai alam, pembuatan bangunan rumah berdasarkan asta kosala kosali, hingga hal-hal spritual. Mitigasi bencana menurut Pasal 1 ayat 6 PP No 21 Tahun 2008 adalah serangkaian upaya untuk mengurangi risiko bencana, baik melalui pembangunan fisik maupun penyadaran dan peningkatan kemampuan menghadapi ancaman bencana. Di Pulau Bali upaya untuk melakukan mitigasi secara spritual sudah dilakukan dengan berbagi ritual seperti mapekelem di Segara, Danau, Gunung serta mendirikan Pura Segara di pesisir pantai sebagai wujud permohonan perlindungan kepada Dewa Baruna.

Secara filosofi masyarakat Bali memiliki naskah yang berbicara khusus untuk membaca tanda-tanda alam, sebab-sebab malapetaka yang terjadi di dunia, jenis-jenis bencana yang terdapat di dunia dan beberapa ciri akan datangnya bencana. Lontar ini juga berisikan berbagai 
upacara yang harus dilakukan oleh masyarakat agar mampu terhindar dari marabahaya khusunya yang berkaitan dengan bencana. Dengan demikian perlu sekiranya dilakukan pengkajian lebih dalam mengenai upaya mitigasi spritual yang tertuang dalam Lontar Roga Sanghara Bhumi dalam menjaga Pulau Bali dari Bencana Alam. Untuk memfokuskan penelitian ini maka dirumuskan menjadi tiga masalah yaitu sebagai berikut :

\section{Pembahasan}

\subsection{Gambaran Umum Teks dan Sinopsis Lontar} Roga Sanghara Bhumi

\subsubsection{Gambaran Umum Teks Lontar Roga Sanghara Bhumi}

Lontar Roga Sanghara Bhumi ditemukan di satu tempat penyimpanan lontar, yaitu di Kantor Pusat Dokumentasi Dinas Kebudayaan Propinsi Bali. Lontar yang disimpan di Kantor Pusat Dokumentasi Dinas Kebudayaan Propinsi Bali disimpan di kropak dengan kode T/XXV/ DISBUD. Lontar Roga Sanghara Bhumi ini ditulis pada lontar yang memiliki panjang $30 \mathrm{~cm}$ dan lebar $3 \mathrm{~cm}$. Jumlah lontar yang ditulis untuk menceritakan tata upacara penyucian bumi adalah sebanyak 92 lembar dengan masing-masing lontar terdiri dari empat baris. Lontar Roga Sanghara Bhumi masih bisa ditemukan di Kantor Pusat Dokumentasi Dinas Kebudayaan Propinsi Bali di ruang penyimpanan lontar.

Lontar Roga Sanghara Bhumi yang disimpan di Kantor Pusat Dokumentasi Dinas Kebudayaan Propinsi Bali telah dialihaksara dan dialihbahasakan atau diterjemahkan. Pemilihan Lontar Roga Sanghara Bhumi yang diperoleh dari Kantor Pusat Dokumentasi Propinsi Bali adalah dalam bentuk salinan teks untuk lebih memudahkan peneliti dalam mengkaji penelitian sastra dan memahami maksud yang terkandung di dalamnya. Lontar Roga Sanghara Bhumi dimasukkan ke dalam kategori tutur karena Lontar Roga Sanghara Bhumi ini memberikan nasihat- nasihat terutama dalam hubungan manusia dengan para dewa dan upacara penyucian bumi.

Lontar Roga Sanghara Bhumi secara tekstual merupakan naskah tradisional yang mengandung upacara penyucian bumi sebagai suatu kearifan lokal. Secara intrinsik tergolong lontar tutur yang disusun dalam bentuk teks menggunakan Bahasa Jawa Kuno atau Bahasa Kawi dengan Bahasa Indonesia sebagai penjelasannya. Tokoh utama yang ditampilkan adalah Bhatara Druwaresi. Bhatara Druwaresi adalah pemimpin para dewa yang berstana di Sorga Surya Loka. Bhatara Druwaresi terkait dengan ajaran Teologi, Durmangala dan Tri Hita Karana karena ketiga ajaran tersebut berkaitan dengan kepercayaan terhadap para Dewa, alamat tidak baik dan upacara penyucian bumi sebagai penetralisir dari kekotoran di bumi.

Dalam Lontar Roga Sanghara Bhumi disebutkan bahwa ajaran Teologi berpusat pada ilmu tentang Tuhan, pengetahuan rohani dan kepercayaan pada Tuhan. Ajaran Durmangala berpusat pada tanda tidak baik, masalah negatif yang ada di bumi, dan isyarat dari alam kepada umat manusia. Sedangkan ajaran Tri Hita Karana (palemahan) berpusat pada hubungan manusia dengan alam, konsep ajaran agama Hindu, falsafah hidup masyarakat Bali. Oleh karena itu, manusia harus hormat kepada Tuhan beserta segala manifestasinya dan selalu menjaga tingkah lakunya agar bumi tidak dilanda kekotoran, jika manusia sudah melaksanakan hal tersebut maka para Dewa tidak akan menyebarkan malapetaka dan wabah penyakit di bumi.

\subsubsection{Sinopsis Lontar Roga Sanghara Bhumi}

Sinopsis Lontar Roga Sanghara Bhumi ini menceritakan tentang bumi yang dilanda kekacauan dimana para Dewa meninggalkan bumi dan digantikan oleh Bhuta. Para Bhuta Kala menggantikan posisi para Dewa dalam memimpin manusia di bumi, para bhuta juga 
merasuki manusia sehingga masyarakat menjadi kebingungan dan terus menerus berperang. Wabah penyakit tiada henti menyerang manusia yang menyebabkan manusia panas menggigil dan banyak yang meninggal. Weda dan mantra tidak dapat digunakan untuk mengobati orang yang sakit. Hendaknya pendeta raja merapalkan weda untuk mengendurkan wabah penyakit tersebut. Mantra yang dirapalkan adalah Akasa Astawa, pendeta yang cerdas hendaknya merapalkan Weda Bayu Astawa dan pendeta yang mempunyai banyak murid hendaknya merapalkan Teja Astawa. Selain itu, bumi juga disucikan dengan 'Oma tirtha' disertai dengan 'nawa ratna' sesuai dengan arah mata angin. Seluruh masyarakat hendaknya juga bersembahyang memohon hidup dan mempersembahkan caru pada setiap pintu gerbang rumah. Apabila pendeta raja mampu mempersembahkan caru tersebut dengan cara yang tepat maka segala bhuta dan penyakit akan merasa takut.

Gempa bumi yang terjadi secara terus menerus harus diupacarai atau dipersembahkan caru sesuai dengan sasih pada saat terjadinya gempa tersebut. Sebagian besar gempa yang terjadi merupakan pengundang wabah penyakit atau sebagai suatu pertanda yang mengarah pada hal yang tidak baik. Namun terdapat juga gempa yang mengarah pada hal yang baik seperti gempa yang terjadi pada sasih Kadasa (April), Kapat (Oktober), dan Kalima (November) dimana gempa yang terjadi pada sasih tersebut merupakan pengundang para Dewa bahwa beliau sangat senang tinggal di bumi. Bumi akan memperoleh kerahayuan dan setiap yang ditanam akan tumbuh subur, selain itu raja yang memimpin juga arif bijaksana dan berbudi luhur. Bhatara Swamandala bersabda kepada yang menjadi pemimpin dunia agar tidak henti-hentinya memohon hidup kepada Hyang Bhagawati pada saat bumi terkena wabah penyakit. Hendaknya pemimpin dunia mengawali memohon pada sasih Kapat (Oktober), Kalima (November), Kanem (Desember), Kapitu (Januari), Kaulu (Februari) dan Kasanga (Maret). Selain itu, setiap orang agar mempersembahkan prani di Pura Dalem, Bale Agung dan Puseh pada setiap sasih Kanem, Kapitu dan Kaulu. Apabila hal tersebut rutin dilaksanakan maka wabah penyakit akan menjauh karena para Dewa berkenan melindungi desa tersebut. Namun apabila hal tersebut tidak dilaksanakan maka manusia akan hancur dan terkena wabah penyakit karena bumi sedang mengalami masa kali yuga. Demikianlah sabda Sanghyang Swamandala yang tersurat dalam sastra.

Tanda-tanda yang teramat kotor adalah sebagai berikut : jika ada binatang yang masuk ke rumah maka hal tersebut merupakan isyarat yang tidak baik bagi raja dimana hal tersebut adalah pertanda bahwa kerajaan beliau akan rusak. Bila ada pelangi yang masuk ke rumah dan meminum air pada istana raja maka hal tersebut adalah pertanda bahwa raja akan hancur. Jika ada pohon besar yang tumbang tidak karena diterjang oleh angin topan maka hal itu merupakan pertanda bahwa rakyat akan mengalami kehancuran. Bila ada gempa yang terjadi secara terus menerus tanpa putus-putusnya maka hal tersebut juga merupakan isyarat yang tidak baik dimana akan terjadi perang besar. Bila ada bintang berekor (bintang kukus) di langit maka hal tersebut mengisyaratkan raja akan tewas dalam pertempuran. Jika ada 'bintang dupa' maka hal itu mengisyaratkan bahwa pendeta akan sakit keras. Bila ada sungai yang dilanda banjir besar dan disertai hujan lebat sehingga pohon beringin yang terdapat disana roboh karena dialiri air sungai yang deras sampai menimbun dasar laut sehingga dasar laut menjadi sangat kotor maka hal itu mengisyaratkan bahwa raja akan tewas dalam pertempuran.

Inilah ciri-ciri bumi ditimpa alamat tidak baik, contohnya adalah kerbau, sapi, kuda, kambing, anjing, babi, banyak, angsa, ayam, segala jenis hewan peliharaan salah pasangan yang artinya bukan dari golongannya yang dijadikan sebagai jantannya dan yang bukan betinanya dijadikan sebagai betinanya. Seperti itulah perilaku binatang. 
Kerbau bersetubuh dengan sapi dan dengan kerbau putih. Kerbau putih bersetubuh dengan kuda. Kambing bersetubuh dengan 'baberes'. Anjing bersetubuh dengan babi. Segala bentuk 'salah timpal' terjadi. Sedangkan yang terjadi pada manusia adalah mengawini kemenakan dan saudara. Hal tersebut merupakan pertanda dari keburukan dunia. Ada juga kelahiran yang bentuknya tidak wajar, orang-orang tidak berdaya, cepat meninggal dan cepat tua, bumi ditimpa wabah secara terus menerus. Padi diserang oleh tikus, air mengecil sedangkan panas teramat sangat di bumi menyebabkan sakit panas, dunia menjadi kurus kering dan raja terganggu dalam memimpin dunia karena kekacauan sedang melanda dunia. Pendeta raja hendaknya waspada dalam menjaga dunia dan segera mengusahakan kebaikan dunia dengan mengadakan upacara. Segeralah mengupacarai bumi agar tidak sampai lewat dari setahun. Caru yang dipersembahkan adalah caru Bhumi Suddha yaitu upacara penyucian dunia dan manusia.

Tanda-tanda tidak baik sebagai pertanda bahwa kematian akan segera datang diawali dengan pertanda tidak baik pada kahyangan. Bila ada kahyangan besar tempat melakukan pemujaan dimana kahyangan tersebut terbakar oleh api dan diantara orang yang melakukan pemujaan di kahyangan tersebut ada yang sedang tertimpa penyakit keras serta terdengar tangisan di rumahnya dan orang lain maupun tetangganya juga mendengar tangisan itu, maka hal tersebut menyatakan kematian. Yang menangis adalah Bhuta Rudita dan dewa rumah dari orang tersebut. Bhuta Rudita datang untuk mencabut atma dari orang yang sakit. Dan bila ada pekerjaan suka maupun duka di desa, tiba-tiba tanpa terduga datang angin ribut yang menghancurkan bangunan. Terhadap orang yang mendapat tandatanda tidak baik seperti itu maka akan mendapat sakit keras. Adapun hal itu harus dibuatkan caru yang bertempat di halaman dan diselesaikan oleh pendeta.

Inilah caru terhadap berbagai alamat tidak baik, seperti tertimpa pohon besar, lumbung roboh, kemasukan binatang, kemasukan pelangi, kemasukan orang mengamuk, disambar petir, diterjang angin kencang dan segala bentuk alamat tidak baik. Upakaranya dibuat seperti 'Caru Manca Sanak', melaksanakan prayascita bumi, melaksanakan upacara penyucian desa, tempat melaksanakan caru itu adalah di jalan simpang empat. Cara mempersembahkan caru itu dengan mendirikan sanggar tawang rong tiga, menaikkan suci lengkap, berisi catur dan wedya. Sedangkan di bawahnya memakai guling babangkit lengkap. Setiap orang menghaturkan sasayut pangambean di rumah masing-masing untuk menyucikan alamat tidak baik dunia dengan menghaturkan upacara 'ngenteg' di sanggar. Bantennya berupa suci 1 buah, canang maraka, ajuman putih kuning, penyuciannya dengan menggunakan nawa ratna, air empul, air salukat, air mangening, dan pakrisan. Demikianlah jumlah air yang digunakan. Caru ini diselesaikan oleh pendeta tetapi bukan pendeta kerajaan karena itu melanggar ketetapan sastra.

Inilah tanda-tanda tidak baik bagi dunia, contohnya kelahiran yang tidak seperti biasanya. Kelahiran yang sekarang berbeda baik dari proses kelahirannya maupun rupanya. Meskipun diperoleh dari kehamilan namun kemudian lahir dalam rupa yang tidak seperti biasa demikian pula proses lahirnya dimana dapat lahir maupun tidak. Yang dapat melahirkan terlihat tidak melahirkan (dalam artian hamilnya hilang). Apabila kelahiran maupun rupanya tidak seperti induk semangnya yang terdahulu maka hal itu menandakan ketidakbaikan pada dunia. Semua yang bisa hamil maupun anak-beranak tidak kelihatan anaknya sebab dunia dan manusia sedang diliputi oleh ketidakbaikan. Makhluk jahat berkeliaran, pencuri galak dan dunia tak karuan sehingga pemimpin dunia menjadi susah. Dewa yang berstana di gunung menyakiti bumi, hal tersebut juga merupakan kehendak dari Bhatara yang berstana di atas langit yaitu Bhatara 
Druwegeni yang bertugas untuk menggerakkan peredaran matahari dan bulan. Beliau juga yang menciptakan segala rupa cahaya dan perputaran baik-buruknya dunia. Apabila raja menginginkan kerahayuan pada negara yang dipimpinnya maka sebaiknya kerusakan itu dihilangkan dengan cara mengadakan upacara selamatan pada penghulunya dunia yaitu melalui caru 'Eka Dasa Rudra'. Setelah mempersembahkan upacara tersebut kemudian dilanjutkan dengan mengadakan upacara diseluruh wilayah kerajaan, mengadakan persembahan kepada dewa di bumi, sembahyang di Pura Bale Agung serta melaksanakan upacara 'Ngusaba Desa' di seluruh wilayah desa untuk mengokohkan bumi. Demikianlah tata caranya agar dunia rahayu. Demikian yang tersurat dalam sastra.

Beginilah seharusnya orang yang ditimpa alamat tidak baik, contohnya sanggar ditimpa pohon besar, terbakar api, tertimpa ulat, ulat emas, ulat perak, ulat tembaga, segala jenis ulat. Jika ada ulat emas, hal itu menandakan bahwa orang yang disayangi akan mendapat bahaya. Jika ada ulat perak, maka hal itu menandakan bahwa tidak henti-hentinya akan mendapat bahaya. Jika ada ulat tembaga, maka hal itu menandakan bahwa akan terjadi cekcok dan banyak yang sakit. Hendaknya segera melaksanakan upacara selamatan agar tidak sampai lewat dari sebulan. Jika lewat dari sebulan maka bencana tersebut tidak akan dapat diredakan. Tingkatan upakaranya untuk golongan bangsawan ataupun sudra adalah tingkat nista maupun madya. Demikian tersebut dalam sastra. Apabila upacara selamatan tidak dilaksanakan, maka bencana tersebut akan datang seperti air mengalir. Bencana tersebut mungkin akan mendatangkan kehancuran karena jiwa manusia telah dikuasai oleh Bhatara Kala. Oleh karena itu, apabila mendapat alamat tidak baik seperti tanda-tanda tersebut sebaiknya jangan dibiarkan saja, melainkan harus tetap waspada. Demikianlah yang disebutkan dalam sastra. Inilah Widhi Sastra Roga Sanghara.

\subsection{Jenis-Jenis Bencana yang disebutkan dalam Lontar Roga Sanghara Bhumi}

Dalam Lontar Roga Sanghara Bhumi disebutkan ada beberapa jenis bencana yang terjadi didunia ini yaitu bencana yang akan terjadi berulang pada setiap sasih nya dan bencana yang akan terjadi melihat tanda atau isyarat yang tidak baik (Durmanggala). Berikut penjelasannya :

\subsubsection{Bencana yang berulang pada setiap sasih.}

Menurut Lontar Roga Sanghara Bhumi bencana gempa bumi biasanya terjadi pada sasih Kadasa (April), Kapat (Oktober), dan Kalima (November). Gempa adalah salah satu peristiwa alam yang amat mengerikan dan membuat manusia traumatis. Gempa dapat terjadi di mana saja, kapan saja, dan terkadang getarannya kecil tidak membahayakan. Apabila getarannya besar, maka gempa dapat membuat bumi luluh lantak (pralaya).

Gempa yang terjadi pada sasih tersebut merupakan pengundang para Dewa bahwa beliau sangat senang tinggal di bumi secara terus-menerus harus diupacarai atau dipersembahkan caru sesuai dengan sasih pada saat terjadinya gempa tersebut. Sebagian besar gempa yang terjadi merupakan pengundang wabah penyakit atau sebagai suatu pertanda yang mengarah pada hal yang tidak baik. Namun terdapat juga gempa yang mengarah pada hal yang baik seperti gempa yang. Bumi akan memperoleh kerahayuan dan setiap yang ditanam akan tumbuh subur, selain itu raja yang memimpin juga arif bijaksana dan berbudi luhur.

Bhatara Swamandala bersabda yang menjadi pemimpin dunia agar tidak henti-hentinya memohon hidup kepada Hyang Bhagawati pada saat bumi terkena wabah penyakit. Hendaknya pemimpin dunia mengawali memohon pada sasih Kapat (Oktober), Kalima (November), Kanem (Desember), Kapitu (Januari), Kaulu (Februari) dan Kasanga (Maret). Selain itu, setiap orang agar mempersembahkan prani di Pura Dalem, Bale Agung dan Puseh pada setiap sasih Kanem, Kapitu 
dan Kaulu. Apabila hal tersebut rutin dilaksanakan maka wabah penyakit akan menjauh karena para Dewa berkenan melindungi desa tersebut. Namun apabila hal tersebut tidak dilaksanakan maka manusia akan hancur dan terkena wabah penyakit karena bumi sedang mengalami masa kali yuga. Demikianlah sabda Sanghyang Swamandala yang tersurat dalam Lontar Roga Sangara Bumi.

Lontar Roga Sanaara Bumi juga berisi tentang bencana alam gempa beserta baik buruknya berdasarkan sasih (bulan) terjadinya gempa tersebut. Berikut uraiannya:

1. Bila sasih kepitu (Januari) datangnya gempa secara terus-menerus, menandakan akan terjadi perang tidak henti-hentinya. Berbagai penyakit akan menimpa masyarakat.

2. Bila sasih kaulu (Februari), dan sasih katiga (September) datangnya gempa secara terusmenerus, ramalannya akan terjadi wabah penyakit sampai banyak orang meninggal.

3. Bila sasih kesanga (Maret) datangnya gempa secara terus-menerus, ramalannya negara tidak akan menentu. Para pembantu meninggalkan tuannya.

4. Bila sasih kadasa (April), ramalannya negara akan menjadi baik. Ini berarti sebagai pengundang Bhatara berbelas kasih kepada manusia.

5. Bila sasih jyesta (Mei) dan sasih sada (Juni), ramalannya akan terjadi banyak orang sakit tidak tertolongkan.

6. Bila sasih kapat (Oktober), sasih kalima (November) ramalannya sebagai pengundang dewata. Para dewa senang tinggal di bumi. Bumi akan mendapat kerahayuan. Segala yang ditanam akan hidup subur dan berhasil (saphala sarwa tinandur). Raja atau pemimpin bijak dan berbudu rahayu.

7. Bila sasih kanem (Desember), ramalannya banyak orang akan jatuh sakit tidak tertolongkan. Untuk menetralisir patut segera dibuatkan upacara persembahan caru selamatan.

Kecuali pengaruh dan ramalan gempa yang terjadi akan mengarah ke kebaikan, maka gempa yang terjadi dan berakibat buruk pada kehidupan harus segera dibuatkan upacara caru selamatan. Gempa yang terjadi pada bulan-bulan yang berbeda dan berpengaruh buruk terhadap kehidupan manusia akibat marahnya para dewa. Untuk jenis upacara persembahan selamatan dan ditujukan kepada dewa siapa, tergantung dari sasih (bulan) berapa terjadinya gempa tersebut.

\subsubsection{Bencana yang terjadi jika melihat Isyarat yang tidak baik (Durmanggala)}

Dalam Lontar Roga Sangara Bumi disebutkan tentang ajaran Durmangala atau suatu isyarat yang tidak yang ditunjukan oleh fenomena alam. Dalam Kamus Bahasa Kawi Durmanggala adalah tanda atau isyarat yang tidak baik (Zoetmulder, 2006 : 239). Durmangala dalam Lontar Roga Sanghara Bhumi merupakan tanda-tanda alamat tidak baik yang diberikan oleh Sanghyang Druwaresi yaitu Dewa yang berstana di atas langit sebagai pertanda bahwa mala petaka akan segera datang. Lontar Roga Sangara Bumi juga menjelaskan ciri-ciri atau tanda-tanda alam yang bermuara akan terjadi sesuatu yang tidak baik. Di samping itu ada pula ciri-ciri atau tanda-tanda alam yang mengarah ke kebaikan. Adapun berikut ini beberapa tandatanda alam yang berarti keburukan akan terjadi:

1. Ada pelangi yang masuk ke keraton dan minum air pada saat hujan. Ini pertanda raja atau pemimpin akan berumur pendek. Untuk mengantisipasi hal seperti itu harus dibuatkan caru (kurban) keselamatan.

2. Ada binatang kijang, menjangan, berlarilari masuk ke desa, masuk ke rumahrumah berkeliling. Ini pertanda buruk bahwa desa itu katadah kala (dimakan bhutakala). Para satwa itu diperintahkan oleh para dewa karena desa itu kotor, tidak ada rohnya bagaikan hutan belantara. Untuk mengantisipasi hal itu, penduduk harus segera membuat upacara selamatan.

3. Kahyangan (tempat pemujaan) ditimpa pohon, terbakar, diterjang angin puyuh, apalagi saat melaksanakan upacara yadnya. Ini pertanda buruk dan akan terjadi bencana yang lebih dahsyat. Masyarakat harus segera membuat upacara prayascita (penyucian).

4. Ada bintang berekor (bintang kukus) di langit. Ini isyarat raja atau pemimpin akan 
kena musibah besar seperti ajal dalam sebuah pertempuran.

5. Bila ada hujan darah, anjing melolonglolong di jalan raya, burung gagak bersuara di malam hari, burung hantu bertarung dengan burung hantu, ada percikan darah di balai-balai atau di lantai. Ini pertanda masyarakat akan tertimpa wabah penyakit mematikan. Untuk menetralisir akibat dari tanda-tanda itu, masyarakat harus segera melakukan upacara selamatan.

6. Segala hewan piaraan manusia seperti sapi, kerbau, kambing, dan sebagainya terjadi salah pasangan. Artinya terjadi perkawinan bukan sesama hewan sejenis, umpama: sapi kawin dengan kerbau, ayam dengan itik, anjing dengan babi, dan sebagainya.

7. Hal salah pasangan juga dapat terjadi pada diri manusia seperti: paman kawin dengan kemenakan, ayah dengan anak, saudara kawin dengan saudara. Ini pertanda bhutakala telah merasuk ke tubuh manusia. Ini harus segera dinetralisir dengan upacara penyucian jagat agar bhutakala kembali ke alamnya.

8. Ada orang melahirkan dengan wujud yang tidak normal atau aneh, pohon kelapa di halaman disambar petir, pintu gerbang juga disambar petir. Semua tanda-tanda ini menandakan dunia telah kotor dan rusak. Untuk menetralisir segera dibuatkan upacara selamatan.

Di samping tanda-tanda yang menunjukkan alam akan terjadi mala petaka atau alamat buruk, dalam Lontar Roga Sanaara Bumi juga berisi beberapa tanda-tanda yang menunjukkan alamat dunia akan baik, yaitu:

1. Apabila ada hujan airnya tanpak kekuningkuningan, ini disebut dengan madewa sudha (pembersihan oleh dewa). Hujan ini pertanda baik terutama terhadap orang yang kejatuhan hujan tersebut.

2. Bila ada hujan airnya keputih-putihan maka ini juga pemtada baik. Desa yang kejatuhan hujan seperti itu akan selamat, seperti segala penyakit akan menjauh.
2.3 Upaya teologis untuk mengurangi Resiko Bencana dalam naskah Lontar Roga Sanghara Bhumi

Jika dicermati dalam pengertian Roga, Sangara dan Bumi dapat diartikan bahwa Roga berarti penyakit, sakit, dan cacat badan. sedangkan Sanghara /Samhara artinya menarik kembali, meniadakan, rusak; lebur, kehancuran, pembinasaan dan sedangkan Bhumi berarti bumi. (Mardiwarsito, 1981: 507). Jadi Roga Sangara Bumi berarti menetralisir atau meniadakan bencana di dunia. Sesungguhnya Naskah Roga Sangara Bumi merupakan sebuah naskah yang memberikan petunjuk kepada manusia dalam menghadapi bencana dengan jalan menjalankan upakara. Hal ini seperti yang tertuang dalam lontar Widhi Sastra yang juga terdapat dalam Lontar Roga Sangara Bumi, disebutkan bahwa masyarakat Bali setiap lima tahun sekali harus melaksanakan upacara tawur agung yang disebut dengan Pancawalikrama. Upacara ini dilaksanakan di Pura Besakih. Dikatakan ini merupakan sabda dan titah dari Bhatara Putrajaya yang berstana di Gunung Agung.

Sebagai konsekuensi apabila upacara itu tidak dilakukan, maka Bhatara Putrajaya akan kembali ke Gunung Mahameru. Dari situ beliau akan menyebarkan segala penyakit mematikan dan dunia dibuat hancur. Saudara bertengkar dengan saudara, terjadi kerusuhan di sanasini. Adapun tujuan dari upacara Tawur Agung Pancawalikrama adalah untuk menghaturkan persembahan berupa jenis-jenis hasil bumi, beberapa satwa, yang dipersembahkan kepada para dewa dan para bhutakala. Kepercayaan masyarakat Bali bahwa dalam kurun waktu lima tahun sudah dapat dipastikan daerah Bali dan juga daerah lainnya telah terjadi kekotoran. Setidak-tidaknya kekotoran pikiran manusia (manacika), perkataan (wakcika), dan perbuatan (kayika), yang menyebabkan bumi kotor (cemer ikang bhuwana). Melalui upacara Tawur Agung Pancawalikrama diharapkan para dewa tidak lagi marah dan dapat memaafkan kelakuan manusia. Bumi menjadi bersih (Kaparisudha). Demikian pula para bhutakala dapat dinetralisir sehingga tercipta kedamaian di bumi (sutrepti ikang rat). 
Apabila terjadi bencana alam secara insidental, dan masyarakat Bali menginginkan kerahayuan jagat, maka dalam Lontar Roga Sangara Bumi disebutkan ada beberapa jenis upacara keselamatan yang dapat dilakukan:

1. Upacara Prayascita, yaitu upacara penyucian bumi pada tatanan yang kecil seperti bangunan pribadi, kebun, dan sebagainya.

2. Guru Piduka, yaitu upacara permohonan maaf kepada para dewa karena ulah manusia bumi menjadi kotor (cemer),

3. Labuh Gentuh, yaitu upacara penyucian bumi yang tingkatnya lebih tinggi dari prayascita.

Di sini terlihat apabila terjadi bencana alam, masyarakat Bali tidak akan ribut sana-ribut sini menyalahkan orang, pemerintah dan lainlain. Bencana yang terjadi justru menyadarkan masyarakat Bali bahwa kita telah banyak mengotori bumi. Para dewa dan bhutakala marah pada manusia. Untuk itu masyarakat Bali lebih banyak menyikapi dengan kearifan lokal yang termanifestasikan di dalam Lontar Roga Sangara Bumi. Upacara-upacara penyucian bumi segera dilakukan sesuai dengan tingkatan-tingkatannya. Mulai dari upacara penyucian bumi tingkat rumah tangga, tingkat desa, tingkat kabupaten/kota, dan tingkat propinsi. Upacara ini ditujukan kepada para dewa, bhutakala, agar sudi memaafkan ulah manusia, mengmbalikan bumi ini menjadi bersih dan suci kembali. Tujuan yang paling penting sudah tentu agar tidak lagi terjadi bencana alam atau dijauhkan dari segala malapetaka.

Jika terjadi Bencana upacara-upacara penyucian bumi juga segera dilakukan sesuai dengan tingkatan-tingkatannya. Mulai dari upacara penyucian bumi tingkat rumah tangga, tingkat desa, tingkat kabupaten/kota, dan tingkat propinsi. Upacara ini ditujukan kepada para dewa, bhutakala, agar sudi memaafkan ulah manusia, mengembalikan bumi ini menjadi bersih dan suci kembali. Tujuan yang paling penting sudah tentu agar tidak lagi terjadi bencana alam atau dijauhkan dari segala malapetaka.

Dalam implementasinya di masyarakat terhadap upaya pembersihan bumi dari mala petaka serta upaya mendapatkan kesejahteraan dunia disikapi dengan memanfaatkan kearifan lokal sesuai dengan desa kala dan patra. Sehingga muncul beberapa sebutan istilah dalam pelaksaan ritual tersebut yang merupakan terjemahan dari implementasi lontar Roga Sanghara Bhumi seperti ; Peneduh Jagat, Pamilayu Bhumi dan Nangluk Merana.

\section{a. Peneduh Jagat}

Berdasarkan kalender Bali hari Kajeng Kliwon yang bertepatan dengan Sasih Kapat merupakan hari yang tepat untuk melaksanakan upacara peneduh jagat. Hal ini sesuai dengan bunyi lontar Dharma Pemaculan, lontar Roga Segara Bumi. Dalam lontar tersebut dikatakan bahwa apabila ada ciri-ciri seperti gempa bumi, wabah penyakit, gerhana, manusia meninggal tanpa sebab, manusia tidak bisa membedakan mana yang baik dan buruk pada saat itu patut dilaksanakan upacara peneduh jagat. Upacara peneduh jagat ini bertujuan agar bumi ini aman tentran dan damai seteleh berbagai peristiwa menimpa dan mengganggu kesejahteraan masyarakat.

\section{a. Pamilayu Bumi}

Pamilayu Bumi adalah wujud ritual secara Hindu dengan tujuan untuk kerahayuan Jagat. "Makna dari ritual itu sebagai permohonan maaf kepada Ida Sang Hyang Widhi Wasa atas situasi di daerah yang banyak bencana alam dan konflik sosial serta pertentangan. Mudah-mudahan bisa lebih diredakan. Terganggunya keharmonisan hubungan manusia dengan Tuhan, manusia dengan alam, dan manusia dengan manusia diharapkan bisa diminimalisir dengan upacara. Selain bencana alam, beberapa kejadian yang terjadi di luar akal sehat manusia, kecelakaan lalu lintas, hingga konflikkonflik sosial yang terjadi di masyarakat perlu disikapi dengan melaksanakan ritual itu. "Sesuai dengan salah satu sastra Agama Hindu yakni Lontar Roga Sanghara Bhumi bahwa kejadian tersebut perlu disikapi dengan menggelar 'Pamilayu bumi' agar terwujudnya keselamatan jagat,

b. Nangluk Mrana 
Upacara Nangluk Mrana (merana) adalah upacara yadnya yang dilaksanakan sebagai permohonan kepada Ida Sang Hyang Widhi, Tuhan Yang Maha Esa agar berkenan menangkal atau mengendalikan gangguan -gangguan yang dapat membawa kehancuran atau penyakit pada tanaman, seperti padi di sawah, hewan maupun manusia sehingga tidak membahayakan lagi. "Nangluk Mrana" berasal dari kata bahasa Bali yang kemungkinan juga mendapatpengaruhbahasa sansekerta.yaitu ; "Nangluk" berarti empangan, tanggul, pagar, atau penghalang; dan "mrana" berarti hama atau bala penyakit. Dan mrana adalah istilah yang umum dipakai untuk menyebut jenis-jenis penyakit yang merusak tanaman. Bentuknya bisa berupa serangga, binatang maupun dalam bentuk gangguan keseimbangan kosmis yang berdampak merusak tanaman. Jadi "nangluk mrana" berarti mencegah atau menghalangi hama (penyakit), atau ritual penolak bala.

Dengan demikian bahwa Lontar Roga Sanghara Bhumi memberikan upaya pencegahan (Mitigasi) secara niskala melalui berbagai rangkaian upakara dengan tujuan bahwa dapat memberikan pengurangan terhadap dampak dari bencana yang terjadi dengan memohon kehadapan Ida Sang Hyang Widhi Wasa. Sehingga masyarakat meyakini bahwa kekuatan diluar kemampuan manusia tersebut akan menghindarkan manusia dari berbagai bencana yang terjadi.

\section{Penutup}

Dari hasil kajian yang dilakukan maka secara singkat diketahui bahwa lontar Roga Sanghara Bhumi berisi tentang sebab-sebab malapetaka atau bencanaterjadi didunia,jenis-jenis malapetaka atau bencana yang dapat terjadi di dunia dan beberapa ciri akan datangnya malapetaka atau bencana, sedangkan jenis-jenis bencana yang disebutkan dalam lontar Roga Sanghara Bhumi yaitu jenis bencana yang berulang setiap sasih nya dan jenis bencana yang terjadi yang dilihat dari isyarat yang tidak baik, dalam konsep lontar Roga Sanghara Bhumi disebut Durmanggala. Upaya-upaya Teologis yang dilakukan dalam menanggulangi bencana yang disebutkan dalam lontar Roga Sanghara Bhumi adalah melakukan upacaraupacara yang ditunjukan kepada Ida Sang Hyang Widhi Wasa dengan tujuan memohon keselamatan seperti melakukan Upacara Prayascita, Guru Piduka, Labuh Gentuh, Peneduh Jagat, Pamilayu Bumi dan Nangluk Mrana. Semua upacara tersebut merupakan upaya (mitigasi) secara teologis dalam mengurangi resiko bencana yang terjadi di muka bumi ini.

\section{DAFTAR PUSTAKA}

Bungin, Burhan. 2001. Metodelogi Penelitian Kualitatif. Jakarta : PT Raja Grapindo Persada

Departemen Pendidikan dan Kebudayaan. 2001. Kamus Besar Bahasa Indonesia. Edisi Kedua. Jakarta : Balai Pustaka

Ratna, Nyoman Kutha. 2008. Teori, Metode, dan Teknik Penelitian Sastra. Yogyakarta : Pustaka Pelajar

Tim Penyusun. 2005. Alih Aksara dan Alih Bahasa Lontar Roga Sanghara Bhumi, Wasista Tattwa, Dewa Tattwa. Denpasar : Dinas Kebudayaan Provinsi Bali

Titib, I Made. 2007. "Teologi Hindu (Brahmavidya) : Studi Teks dan Konteks Implementasi". Surabaya : Paramita.

PP Nomor 21 Tahun 2008 Penyelenggaraan Penanggulangan Bencana.

\section{Sumber Media :}

beritabali.com tanggal selasa, 24 November 2015. sains.kompas.com tangal selasa, 25 November 2015 